\title{
Energy savings achieved from recommissioning a research and development center
}

\author{
Xinjiang Huang ${ }^{1}$, Chenggang Liu $^{1, \mathrm{a}}$ and Yuyang Miao ${ }^{1}$ \\ ${ }^{1}$ School of Environmental Science and Engineering, Suzhou University of Science and Technology, 215009, Suzhou, Jiangsu, China
}

\begin{abstract}
The recommissioning is performed for a research and development (R\&D) center located in Suzhou. The hardware problems of Heating, Ventilation and Air Conditioning (HVAC) system and software problems of Electrical Monitoring and Control System (EMCS) were found. The recommissioning measures were generated and control logic in EMCS was optimized and improved. The saving of about $121 \mathrm{~kW}$ for chilled water consumption, $181 \mathrm{~kW}$ for hot water consumption and $1450 \mathrm{kWh} / \mathrm{D}$ for electricity consumption from recommissioning were achieved from recommissioning measures.
\end{abstract}

\section{Introduction}

According to the statistics of recent years, the energy consumption of public buildings accounts for $27.9 \%{ }^{[1]}$. Building energy saving will be the eternal theme under the background of energy-saving and low-carbon society, and energy saving of HVAC system is the main character of building energy saving ${ }^{[2]}$. Many researchers analyzed the HVAC system from the perspective of planning, design, construction, commissioning, operation and equipment maintenance, and achieved the energy saving effect of about $10 \%$ to $30 \%{ }^{[3-7]}$. Recommissioning is performed for a research and development center as an example in this paper.

The research and development center is a 3-story building with a basement located in Suzhou Industrial Park. The total floor area of the building is $8,200 \mathrm{~m}^{2}$. The basement has a refrigerating station. The first floor is mainly offices and a restroom. The second floor is two physical labs and an office. The third floor houses twelve chemistry labs.

There are 5 air handling units (AHUs) in the R\&D center as shown in figure 1. AHU-1, AHU-2 and AHU-3 are single-duct variable air volume (SDVAV) systems with the reheat terminal boxes and direct digital control (DDC), serving the main parts of the 1st through the 3rd floors respectively. AHU-4 is an air handling unit with local pneumatic control, which treats the outside air for AHU-1, 2 and 3. AHU-5 is a make-up air handling unit with heating coil only and local pneumatic control, serving the hoods on the 3rd floor. There are two chilled water pumps with variable frequency drives (VFD) and two constant speed hot water pumps in the basement. There are 36 exhaust fans on the roof of the main part of the building. Twenty-six are used for exhaust in the laboratories on the 3rd floor, and others are for restroom and other room exhaust. These AHUs and exhaust fans run 24 hours per day, 7 days a week.

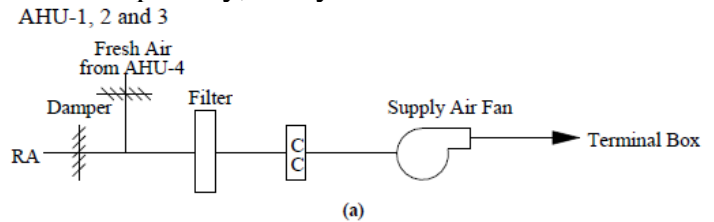

AHU-4 (Outside Air Handling Unit)

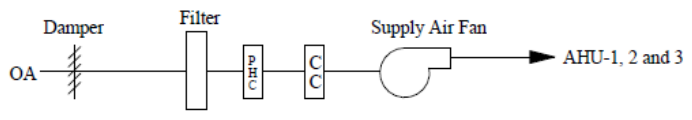

(b)

AHU-5 (Make-Up Air Handling Unit)

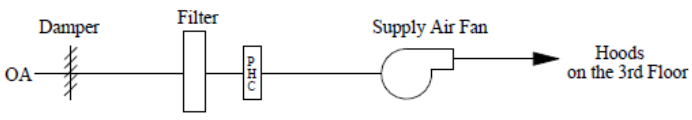

(c)

Figure 1. The schematic of the AHUs

Major recommissioning activities started on $3 / 20 / 2016$ and ended on $6 / 30 / 2016$.

\section{Problems and measures for the HVAC system}

\subsection{Concerns identified of the water system}

\subsubsection{Chilled water}

The meter needs to be calibrated. The wrong value of the factor $\mathrm{K}$ of 66.7 was put in the control program to

*Corresponding author: ${ }^{a}$ cliu1977@163.com 
calculate the chilled water flow rate and changed to 70 as provided by the manufacture.

\subsubsection{Hot water}

The building hot water difference pressure (DP) was $448 \mathrm{kpa}(\mathrm{Ps}=696 \mathrm{kpa}, \mathrm{Pr}=248 \mathrm{kpa})$. It is recommended that VFDs be installed for two hot water pumps. This DP is too high to protect reheat control valves on the terminal.

\subsection{Concerns identified of AHUs}

The detailed analysis of AHUs is shown in the table 1.

Table 1. Problems and issue of all AHUs.

\begin{tabular}{|c|c|}
\hline No. & Problems and issue \\
\hline AHU-1 & $\begin{array}{l}\text { The static pressure of } 0.36 \mathrm{kpa} \text { was measured } \\
\text { when the fan was at maximum speed. The design } \\
\text { static pressure is } 0.98 \mathrm{kpa} \text {. However the flow rate of } \\
57800 \mathrm{~m}^{3} / \mathrm{h} \text { matched the design. }\end{array}$ \\
\hline AHU-2 & No problem \\
\hline AHU-3 & No problem \\
\hline AHU-4 & $\begin{array}{l}\text { The outside air inlet and the filter are dirty and } \\
\text { need to be cleaned. The preheat control valve is } \\
\text { rusted and keeps open position. When push to } 125 \mathrm{kpa} \\
\text { it did not move. The chilled water control valve is a } \\
\text { normally open valve and disconnected because the } \\
\text { controller is not working properly. The controller for } \\
\text { air flow control is not working properly too. }\end{array}$ \\
\hline AHU-5 & $\begin{array}{l}\text { It had been off for approximately five years. The } \\
\text { controller for the inlet vanes control is broken. The } \\
\text { preheat valve controller couldn't give the correct } \\
\text { output. The outside air damper actuator arm needs to } \\
\text { be replaced. }\end{array}$ \\
\hline
\end{tabular}

\subsection{Major recommissioning activities on HVAC Hardware}

All five AHUs all exhaust fans, building chilled water and hot water systems were checked. The make-up air handling unit which had been off for approximately five years was turned on after the air flow controller is replaced and a balance is performed for 3rd floor.

Then all the thermostats, reheat control valves and terminal boxes need to be checked. All sixty seven thermostats were checked. Sixteen of them work. Thirty three thermostats were calibrated, and eighteen thermostats were replaced. All sixty VAV dampers were checked. Sixteen dampers were stuck and need of repair.

All forty reheat control valves were checked. Twenty valves were stuck or were allowing water to flow when they were shut. Exhaust measurement and an air balance for the chemical labs on the 3rd floor were performed. Chilled water flow meter was verified and the flow meter transmitter was calibrated.

Hot water control valve of AHU-4 needs to be replaced, because it was stuck. Twenty reheat control valves of terminal boxes need to be fixed, because they were leaking or stuck. VFD for two hot water pumps needs to be installed. The reason is that $38 \mathrm{~m}$ (370kpa) head of the pumps is too high in entire year for the R\&D center. Meanwhile the higher pressure will damage reheat control valves of the terminal boxes. The pneumatic controls for AHU-1 and AHU-2 need to be fixed. The cooling coils of AHU-3 on the 3rd floor need to be replaced, because the discharge air temperature was over $16^{\circ} \mathrm{C}$ which is too high for dehumidification in hot and humid weather. All exhaust fans on the roof need to be checked in mechanic, because the CFM for most exhaust fans doesn't match design.

\section{Optimization scheme of the control system}

\subsection{Existing control schemes}

\subsubsection{Chilled water pumps and control valve control}

The difference pressure flow meter $\left(\mathrm{DP}_{\mathrm{m}}\right)$ is installed and chilled water flow $\left(\mathrm{m}^{3} / \mathrm{h}\right)$ can be calculated from the equation SQRT $\left(\mathrm{DP}_{\mathrm{m}}\right)^{*} 70^{[8]}$ with the reading of $\mathrm{DP}_{\mathrm{m}}(\mathrm{kpa})$ from the flow meter.

Chilled water building DP setpoint should be reset from $100 \mathrm{kpa}$ to $370 \mathrm{kpa}$ according to the chilled water flow from Table 2 .

Table 2. Building DP reset schedule.

\begin{tabular}{|c|c|c|c|c|c|c|}
\hline water flow $\left(\mathrm{m}^{3} / \mathrm{h}\right)$ & 0 & 38 & 76 & 114 & 152 & 188 \\
\hline DP $(\mathrm{kpa})$ & 100 & 113 & 146 & 200 & 275 & 370 \\
\hline
\end{tabular}

The chilled water control valve is modulated to be fully open before the pump is on. Chilled water pump \#1 will be on and speed will be increased to maintain the building DP at its setpoint. Chilled water pump \#2 will be on and speed will be increased to maintain the building DP at its setpoint, after chilled water pump \#1 is at maximum speed.

\subsubsection{Chilled water valve control for AHUs 1, 2 and 3}

Chilled water valve is modulated to maintain the cold duct temperature at its setpoint of $16^{\circ} \mathrm{C}$ constant value.

\subsubsection{Fan speed control for AHUs 1, 2 and 3}

Obtain the cold duct static pressure. The fan speed is varied to maintain the static pressure at a setpoint of $0.67 \mathrm{kpa}$.

\subsubsection{The issues of the old control scheme}

The building DP setpoint is too high and needs to be reset. For example, Building DP of $100 \mathrm{kpa}$ is not necessary when the flow rate is $0 \mathrm{~m}^{3} / \mathrm{h}$. The cold duct temperature setpoint is $16^{\circ} \mathrm{C}$ all year. It will make the interior zone of the building cold during winter. The cold duct temperature setpoint should be reset according to the outside air temperature. Fan speed is controlled to maintain the static pressure at its setpoint and the setpoint is a constant value of $0.67 \mathrm{kpa}$. The static pressure setpoint should be reset according to the outside air temperature. 


\subsection{New control schemes}

\subsubsection{Chilled water pump, control valve and bypass valve control}

The chilled water pump speed is controlled to maintain the building DP at its setpoint. The building DP setpoint is reset according to outside air temperature instead of chilled water flow as shown in Table 3.

Table 3. Chilled water building DP.

\begin{tabular}{|c|c|c|c|c|c|}
\hline OA Temp $\left({ }^{\circ} \mathrm{C}\right)$ & 6 & 12 & 20 & 27 & 35 \\
\hline DP setpoint $(\mathrm{kpa})$ & 35 & 70 & 100 & 140 & 170 \\
\hline
\end{tabular}

\subsubsection{Chilled water valve control for AHUs 1, 2 and} 3

The chilled water valve is controlled to maintain cold duct temperature at its setpoint. Cold duct temperature setpoint is reset according to outside air temperature instead of a constant value of $16^{\circ} \mathrm{C}$ as shown in Table 4 .

Table 4. New reset schedule of cold duct temperature.

\begin{tabular}{|l|l|l|l|l|}
\hline OA Temp $\left({ }^{\circ} \mathrm{C}\right)$ & 15 & 20 & 25 & 35 \\
\hline $\mathrm{T}_{\text {cd }}$ setpoint $\left({ }^{\circ} \mathrm{C}\right)$ & 20 & 18 & 18 & 16 \\
\hline
\end{tabular}

\subsubsection{Fan speed control for AHUs 1, 2 and 3}

The fan speed is controlled to maintain the static pressure at its setpoint. The static pressure setpoint is set according to outside air temperature instead of a constant value of $0.67 \mathrm{kpa}$ as shown in Table 5 .

Table 5. New reset schedule of the static pressure.

\begin{tabular}{|l|l|l|l|l|l|}
\hline \multicolumn{2}{|c|}{ OA Temp $\left({ }^{\circ} \mathrm{C}\right)$} & 15 & 20 & 25 & 35 \\
\hline \multirow{4}{*}{$\begin{array}{l}\text { Static Pressure } \\
\text { setpoint (Pa) }\end{array}$} & AHU-1 & 265 & 320 & 320 & 370 \\
\cline { 2 - 6 } & AHU-2 & 400 & 490 & 490 & 610 \\
\cline { 2 - 6 } & AHU-3 & 490 & 560 & 560 & 670 \\
\hline
\end{tabular}

\section{Saving analysis}

Recommissioning activities started on 3/20/2016 and ended on 6/30/2016. All of the data comparisons are between pre-recommissioning and post recommissioning. The data for chilled water, hot water and electricity consumption is shown in figure 2 through figure 4 . The pre-recommissioning data, 3/19/2015-3/19/2016, is marked in black points. Post recommissioning data, $4 / 24 / 2016-6 / 5 / 2016$, is marked in grey points.

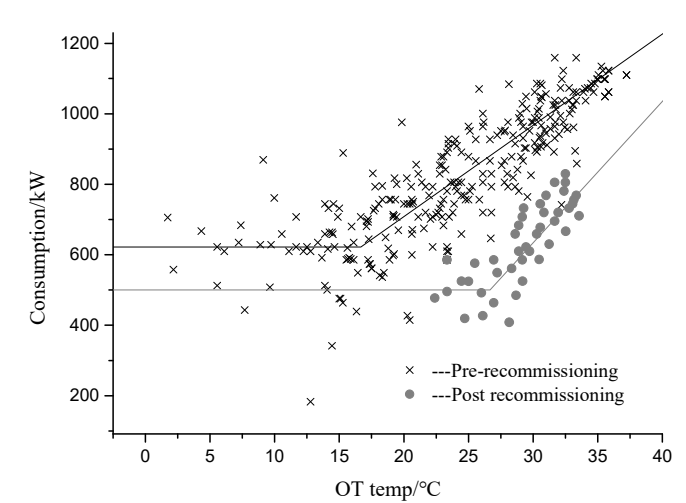

Figure 2. Consumption of chilled water

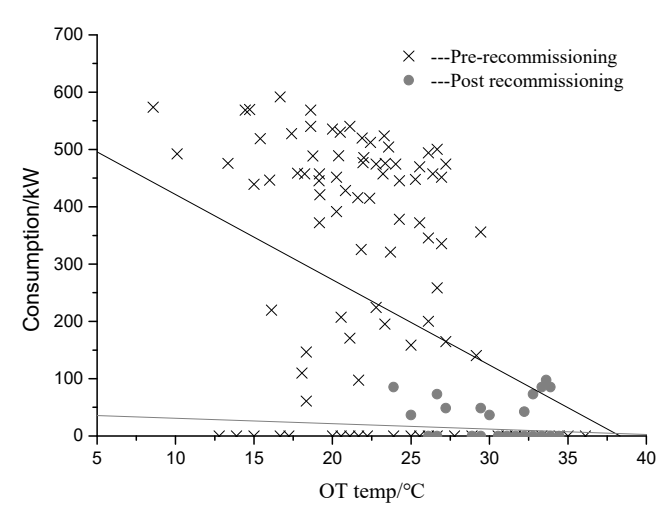

Figure 3. Consumption of hot water

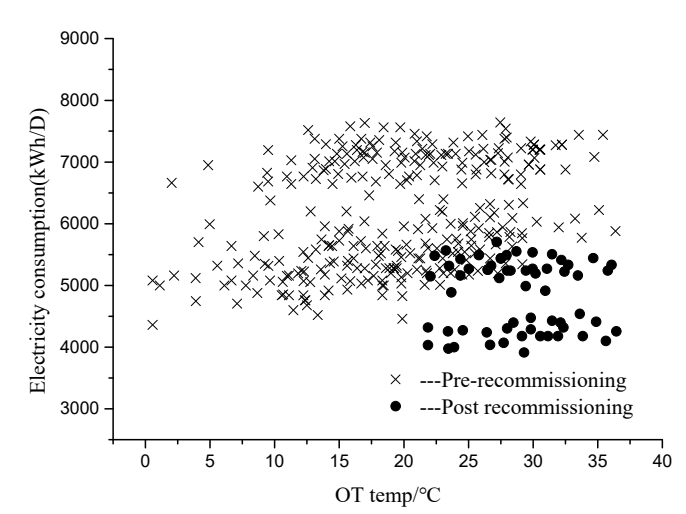

Figure 4. Electricity consumption of HVAC system

As is known from figure 2 to figure 4 that chilled water consumption reduced by an average of about $121 \mathrm{~kW}$ or $20 \%$, hot water consumption reduced by an average of about $181 \mathrm{~kW}$ or $20 \%$ and electricity consumption reduced by an average of about 1450 $\mathrm{kWh} / \mathrm{D}$ or $20 \%$.

The savings are the result of recommissioning activities such as new control scheme, air balance, repairing leaking valves, replacing bad thermostats and turning on the make-up air handling unit.

\section{Conclusions}

Through recommissioning activities, the energy saving opportunities were found for the research and development center. From investigation and analysis, 
both of hardware and software problems were found and optimized. Significant energy saving effect was achieved from recommissioning measures.

\section{References}

1. Y. Jiang, C. Peng, S. Hu, Construction Science and Technology, Classification of energy consumption in China, 14, 22-26(2015)

2. X. Wu, HV\&AC, Considerations in energy efficient design of HVAC systems, 42, 7, 1-11(2012)

3. K. Ma, T. Zhao, D. Shen, M. Liu, Procedia Engineering, Web Based Chiller Plant Optimal Control-A Case Study, 205, 967-974(2017)

4. J. Yan, J. Feng, HV\&AC, Air conditioning system energy efficiency retrofitting of a large-scale shopping mall in Guangzhou. 44, 5, 87-91(2014)
5. S. Pan, H. Wang, F. Pei, L. Yang, X. Zhang, Energy Procedia, An Investigation on Energy Consumption of Air Conditioning System in Beijing Subway Stations, 142, 2568-2573(2017)

6. Raad Z. Homod, Renewable Energy, Analysis and optimization of HVAC control systems based on energy and performance considerations for smart buildings, 126, 49-64(2018)

7. L. Qiao, W. Zhang, Q. Zhou, L. Wang, HV\&AC, Air conditioning system optimization design in a commercial building, 43, 9, 79-82(2013)

8. Y. Sheng, Z. Miao, J. Zhang, X. Lin, H. Ma, Energy and Buildings, Energy consumption model and energy benchmarks of five-star hotels in China, $165,15,286-292(2018)$ 